\title{
Efficacy and safety of medium and high doses of mometasone furoate/formoterol (MF/F) combination treatment in subjects with severe persistent asthma
}

\author{
Steven F Weinstein ${ }^{1 *+}$, Kevin R Murphy ${ }^{2}$, Jonathan Corren ${ }^{3}$, Hendrik Nolte ${ }^{4}$, Martha V White ${ }^{5}$ \\ From Canadian Society of Allergy and Clinical Immunology Annual Scientific Meeting 2010 \\ Victoria, Canada. 4-7 November 2010
}

\section{Background}

Multiple strengths of mometasone furoate/formoterol (MF/F) MDI combination therapy are under investigation as new treatments for asthma. We report efficacy/ safety findings from a 3-month MF/F study in subjects with severe asthma.

\section{Materials and methods}

This was a 3-month, randomized, double-blind, parallelgroup, multicenter study with a 2-3-week open-label, run-in period of mometasone furoate (MF) $400 \mu \mathrm{g}$ twice-daily (BID). Subjects ( $\geq 12$ years) were randomized to MF/F (200/10 $\mu \mathrm{g}$ or $400 / 10 \mu \mathrm{g}$ BID) or MF (400 $\mu \mathrm{g}$ BID). The primary endpoint was the area under the curve (AUC) of the change in serial $\mathrm{FEV}_{1}$ (0-12 hours) for MF/F $400 / 10 \mu \mathrm{g}$ vs MF $400 \mu \mathrm{g}$ from baseline to Week 12. Adverse events (AEs) and other clinical safety measures were recorded.

\section{Results}

A total of 728 subjects (mean: age $=47.9 \mathrm{y}$, asthma duration $=14.0 \mathrm{y}, \mathrm{FEV}_{1} \%$ predicted $=66.3$, reversibility $=$ $22.9 \%$, Asthma Control Questionnaire $[\mathrm{ACQ}]$ score $=$ 1.93) were randomized. Improvements in mean changes from baseline in $\mathrm{FEV}_{1} \mathrm{AUC}_{0-12 \mathrm{~h}}(\mathrm{~L} \times \mathrm{h})$ at Week 12 were MF/F 200/10 $\mu \mathrm{g}=3.59$, MF $/ \mathrm{F} 400 / 10 \mu \mathrm{g}=4.19$, and MF $400 \mu \mathrm{g}=2.04$, with both $\mathrm{MF} / \mathrm{F}$ doses significantly better than MF $(\mathrm{p}<0.001)$. These $\mathrm{FEV}_{1} \mathrm{~s}$ correspond to average hourly increases of $0.30,0.35$, and $0.17 \mathrm{~L}$, respectively. MF/F was associated with rapid ( $<5 \mathrm{~min}$ ) and sustained improvement in lung function. The percentage of subjects experiencing asthma deterioration (ie, severe asthma exacerbation) was $12.4 \%$ (MF/F 200/10 $\mu \mathrm{g}$ ), 12.2\% (MF/F 400/10 $\mu \mathrm{g}$ ), and 18.3\% $(\mathrm{MF} 400 \mu \mathrm{g})$. There were no notable differences in AEs between the groups.

\section{Conclusions}

Both medium- and high-dose MF/F combination therapy led to significantly greater improvements in lung function compared with high-dose MF monotherapy in severe asthmatics.

\section{Author details}

${ }^{1}$ llergy and Asthma Specialists Medical Group and Research Center, Huntington Beach, CA, 92647, USA. ²Boys Town National Research Hospital, Boys Town, NE, 68130, USA. ${ }^{3}$ Allergy Medical Clinic, Research Division, Los Angeles, CA, 90025, USA. ${ }^{4}$ Merck Research Laboratories, Kenilworth, NJ, 07033, USA. Institute for Asthma and Allergy, Wheaton, MD, 20902, USA.

Published: 22 December 2010

doi:10.1186/1710-1492-6-S2-P34

Cite this article as: Weinstein et al:: Efficacy and safety of medium and high doses of mometasone furoate/formoterol (MF/F) combination treatment in subjects with severe persistent asthma. Allergy, Asthma and Clinical Immunology 2010 6(Suppl 2):P34.

\footnotetext{
* Correspondence: sfwocallergy.com

† Contributed equally

${ }^{1}$ Ilergy and Asthma Specialists Medical Group and Research Center,

Huntington Beach, CA, 92647, USA

Full list of author information is available at the end of the article
} 